\title{
Seasonal Theory of COVID-19; One-Year Observation
}

\author{
Azri Salih Haji Sgery', Yousif Maan Hadi', Amer Abdalla Goreal ${ }^{2 *}$
}

\author{
IInternal Medicine and Surgery, College of Medicine, University of Duhok, Iraq. \\ 2Department of Medical Microbiology, College of Medicine, University of Duhok, Kurdistan Region, Iraq. \\ *Correspondence to: Amer Abdalla Goreal (E-mail: amer.goreal@uod.ac)
}

(Submitted: 10 October 2021 - Revised version received: 16 October 2021 - Accepted: 29 October 2021 - Published online: 26 December 2021)

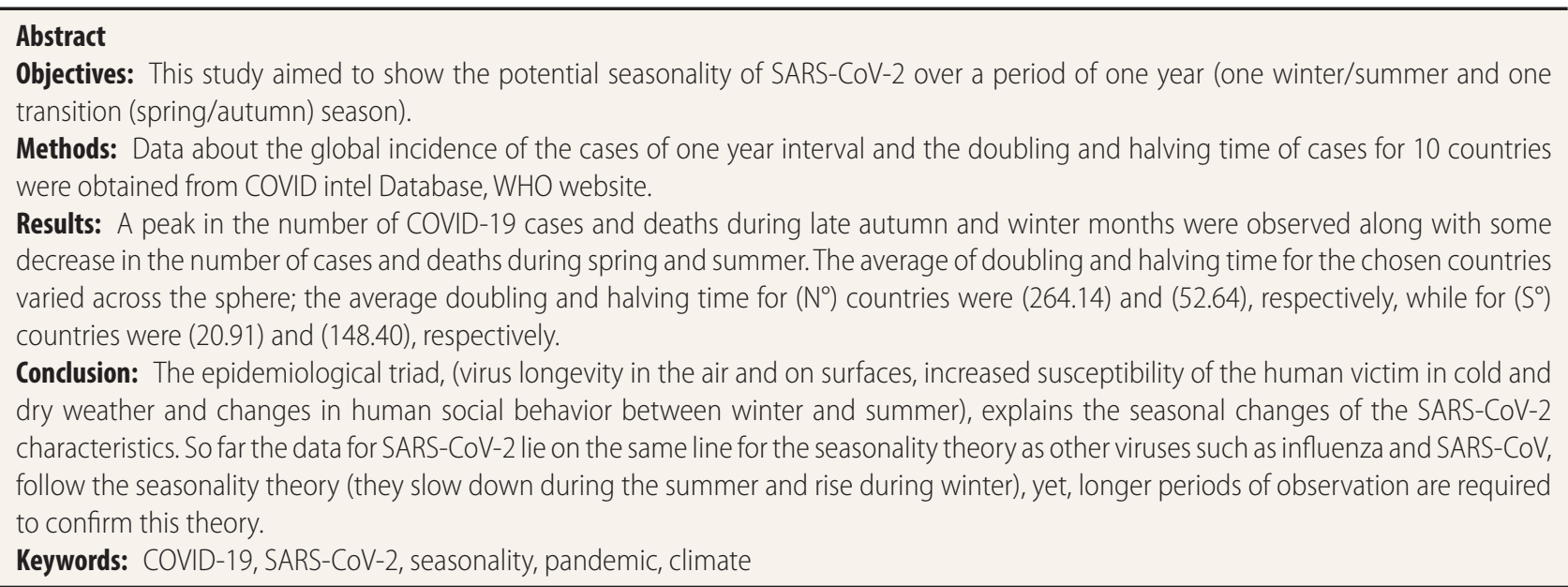

\section{Introduction}

The novel coronavirus (COVID-19) is an infectious and contagious disease caused by the severe acute respiratory syndrome 2 (SARS-CoV-2). The first human case of COVID-19 was reported by officials in Wuhan city, China, in December 2019. ${ }^{1}$ The causative organism of COVID-19, SARS-CoV-2, which is one of the seven viruses that belongs to Coronaviridae family, was identified and linked to COVID-19 in the first quarter of $2020 .^{2}$ The virus spread rapidly worldwide, and by March 11, 2020, COVID-19 was declared as a global pandemic by the World Health Organization (WHO). ${ }^{3}$ The total number of confirmed COVID-19 cases by March 11, 2020 reached 120,926 cases with 4368 total number of deaths, and globally, as of 11:15 AM CET, March 12, 2021 there have been 118,058,503 confirmed cases of COVID-19, including 2,621,046 deaths received by $\mathrm{WHO}$ from national authorities. ${ }^{4}$

With the increase in the cases associated with COVID-19 and public fear, many theories and were developed and/or adopted, one of which was whether SARS-CoV-2 that's responsible for COVID-19 is from the viruses that undergoes seasonal changes.

Flu viruses, come in seasons and manifestations peak during fall and winter, comprise well-known examples about this phenomenon. These viruses are widely known as seasonal viruses, hence they became known as the seasonal influenza viruses and their season as the flu season. While influenza viruses circulate year-round, the duration between December and February is the period in which the flu activity peaks most years, however, their activity may last until May. These flu viruses undergo seasonal variation regarding health impact including: number of infections, hospitalizations, and deaths, supporting that ancient phenomenon about contagious diseases even more. ${ }^{6}$ Hence, the concept of seasonal changes for COVID-19 began to be more widely believed worldwide. However, to the date, there is no solid evidence that COVID-19 will or will not wax and wane seasonally. Yet, researches were done supporting the evidence. Nevertheless, the infectious characteristics of SARS-CoV-2, (incidence, mortality, recovery cases, active cases, testing rate, and hospitalization), varied between countries and were dependent on 3 main factors - Average spring temperature, latitude (distance north or south of the equator) and longitude (distance east or west of the prime meridian)-; COVID-19 characteristics decreased as temperature increased, decreased as latitude decreased, and were not affected by longitude.

Over one year in COVID-19 pandemic, seasonality concept for other viruses and the difference in the infectious characteristics were the reason for this study. This study aimed to show the potential seasonality of SARS-CoV-2 over a period of one year (one winter/summer and one transition (spring/ autumn) season).

\section{Methodology}

This study was done in form of a retrospective cohort study analyzing global COVID-19 cases. Data about the incidence of SARS-CoV-2 infection over one year interval were obtained from the official World Health Organization (WHO) website and were analyzed. The incidence of cases was taken in the form of cases/week from the website. From every 4 weeks in a month the last one was taken and the data were obtained from March, 30th 2020 to March 29th 2021.

A total number of 10 countries were chosen, 5 from each half of the sphere, to obtain the doubling time and halving time of each country depending on the weekly incidence in a time range of 1 year (March 11, 2020 - March 11, 2021); United States of America (US), United Kingdom (UK), Italy, 
France and Spain were the countries chosen from the northern hemisphere and Australia, New Zealand, Brazil, Argentina and Chile were chosen from the southern hemisphere.

Doubling times and halving times are useful measures in assessing the rate at which a disease spreads. These values can change depending on context and public health measures put in place. Doubling time - defined as the time it would take for the number of new daily cases to double which is a key variable in understanding the speed of growth of an outbreak. Conversely, once an epidemic has reached its peak and the number of daily new cases begins to decrease, these growth models are used to characterize the halving time of the epidemic, defined as the time taken for the number of new daily cases to halve.

\section{Results}

Tables 1 and 2 shows the doubling and halving time of a total 10 countries from northern $\left(\mathrm{N}^{\circ}\right)$ and southern $\left(\mathrm{S}^{\circ}\right)$ hemispheres, respectively. The highest doubling time was seen for Italy $\left(\mathrm{N}^{\circ}\right)$ (1075.38 days) and the lowest was seen in Chile $\left(\mathrm{S}^{\circ}\right)$ (17.97 days) although Australia and New Zealand were having none. Additionally, the highest halving time was seen in New Zealand $\left(\mathrm{S}^{\circ}\right)$ (291.13 days), while the lowest seen in Spain $\left(\mathrm{N}^{\circ}\right)$ (13.33 days). The average doubling time was lower for countries in southern hemisphere (20.91) than for northern hemisphere (264.14), while the average halving time was lower for countries in the northern hemisphere (52.64) than for southern hemisphere (148.40).

Chart 1 shows the global and regional incidence of COVID-19 cases in a 4 week period, from March 1st, 2020 to May 1st, 2021. Global weakly incidence of COVID-19 shows peak in incidence at different times for different regions until March 15; America (Dec-Jan), Europe and Eastern Mediterranean (Nov-Dec), South East Asia (Sept-Oct), Africa (Jan) and Western Pacific (Jan-Feb).

\section{Discussion}

The uncertainty about SARS-CoV-2 seasonality remained the center of attention of many researchers, especially after the preliminary laboratory trials suggested the virus survives longer outside the human body than other viruses. ${ }^{8}$

As it is shown in the plot, the characteristics of the cases rose in the last quarter of 2020 - beginning of 2021. Factors that might have an effect on this rise can be explained by the epidemiologic triad, which is the traditional model for infectious disease: pathogen (agent) factors, host factors (susceptibility), and factors of the environment that brings the host and agent together. Among the pathogen factors: genetics, mode of transmission, mutations, duration of the infection and the window of transmissibility. Host factors: human behavior as hygiene, personal choices, age, and sex. Other host factors include: genetic composition, nutritional and immunologic status, anatomic structure, presence of disease or medications, and psychological makeup. Environmental factors include: climate, humidity, distance from the equator, and socioeconomic factors such as crowding, sanitation, and the availability of health services.

Although one year does not give definite evidence, temperature seems to affect the viral characteristics. The variation in temperature in different regions of the world is created by solar energy received which varies between regions and seasons. For instance, the temperature in Brazil varies less than other regions as it's closer to the equator and has a generally warmer climate, hence, the incidence of COVID-19 cases does not vary much with seasons of the year, unlike the United States. ${ }^{4,7}$ On the same line, a study in Indonesia showed that weather affected disease incidence and it might have been an important factor in decreasing the number of COVID-19 cases in that country. ${ }^{10}$

Viral disease slows down during the summer for certain viruses, including influenza and SARS-CoV, additionally; low temperatures were negatively correlated with incidence of cases for these viruses. ${ }^{7}$ This correlation is usually seen with

Table 1. Peak of cases in season, doubling and halving time per country in the northern hemisphere

\begin{tabular}{lcccc}
\hline Country & Hemisphere & Doubling time (days) & Halving time (days) & Peak of cases \\
\hline France & $\mathrm{N}^{\circ}$ & 48.95 & 101.65 & Autumn \\
Italy & $\mathrm{N}^{\circ}$ & 1075.38 & 106.39 & Autumn \\
Spain & $\mathrm{N}^{\circ}$ & 69.46 & 13.33 & Winter \\
United Kingdom & $\mathrm{N}^{\circ}$ & 58.99 & 17.45 & Winter \\
United States of America & $\mathrm{N}^{\circ}$ & 67.93 & 24.38 & Winter \\
Average & & 264.14 & 52.64 & \\
\hline
\end{tabular}

Table 2. Peak of cases in season, doubling and halving time per country in the southern hemisphere

\begin{tabular}{lcccc}
\hline Country & Hemisphere & Doubling time (days) & Halving time (days) & Peak of cases \\
\hline Australia & $S^{\circ}$ & - & 48.68 & Summer \\
Argentina & $S^{\circ}$ & 18.88 & 171.69 & Autumn \\
Brazil & $S^{\circ}$ & 67.71 & 37.05 & Winter \\
Chile & $S^{\circ}$ & 17.97 & 193.46 & Summer \\
New Zealand & $S^{\circ}$ & - & 291.13 & - \\
Average & & 20.91 & 148.40 & \\
\hline
\end{tabular}




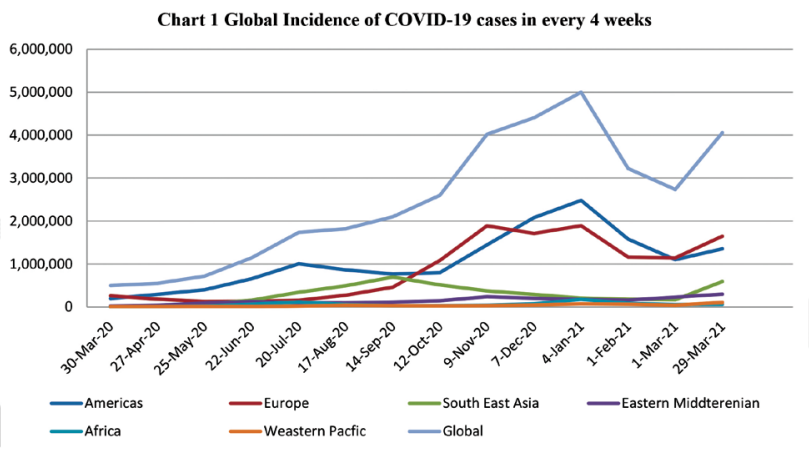

Linear chart (1). Number of weekly confirmed COVID-19 cases

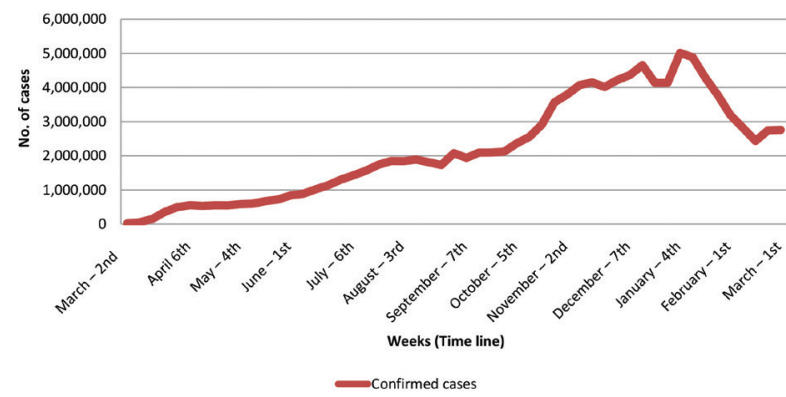

several respiratory viruses and indicates the ability of the virus to survive and spread better in these conditions. This was seen with SARS-CoV epidemic back in 2003. ${ }^{7}$ Despite that the data are on the same line for SARS-CoV-2 so far, yet, we cannot confidently declare it to belong to the same group.

Having the seasonality feature is an important predictor for the occurrence of subsequent waves. If SARS-CoV-2 is proven to be seasonal and the onset of its season was predicted, herd immunity can be established early via vaccines, prior to the onset of the seasonality-sensitive second wave of infections that are seen yearly in the viral specific season, to prevent the high incidence of the cases and/or social life restrictions. Will COVID-19 become an annual occurrence, like many other viral respiratory diseases?

In this study, the global linear chart of weekly confirmed COVID-19 cases support the idea of seasonality, although the incidence of cases was increasing in summer, a jump was observed during the late autumn, i.e. November specifically, and winter period. Hence, it's likely that COVID-19, like other common respiratory viruses, influenza for instance, follows a seasonal pattern. The steady increase that was recorded from May until August was likely due to the loosening of infection control measures protocol. ${ }^{11}$

The first outbreak that happened in China, followed by epidemics in Iran, Italy and most of Europe and the USA happened during the coldest months in the year for these countries, and that was distributed within a narrow climatic band.

Timing of peaks differs between countries at different latitudes due to the difference in their mean temperatures in various months of the year. The peaks usually happen in periods when the mean temperature is between $2-10^{\circ} \mathrm{C}$. This might be in winter for one country, like Spain, France, USA, for example (usually on a latitude of $30-50^{\circ} \mathrm{N}$ ), while it might be another season for some other countries, like those in the southern hemisphere, that had a rise and peak in the austral late summer to early autumn..$^{12,13}$

Doubling times and halving times are measures used to assess the rate of a disease spread. The values changes depending on context and public health measures put in place. Depending on these values, countries that are in a northern hemisphere as US, UK, Spain, France ... etc. shows peaks of doubling time during autumn-winter seasons. These measures show a semi-baseline during warm climate of the preceding countries as US and UK for instance. For countries in the southern hemisphere, the concept works the same except for timing; Argentina has the peak in autumn and Australia in summer, for instance.

Many studies have tried to identify the effects of climate on COVID-19 incidence, using data that was available to them, but failed to prove or deny a link between the two. These studies were all done during 2020, before going through one year of COVID-19 pandemic, and thus they used space-fortime substitution to compensate for the fact that they had no single country that went through a full year in the presence of COVID-19 (they used the difference in climate between countries as a replacement for the evolution of COVID-19 over time in a single location). ${ }^{14-17}$ On the other hand, in our study, we used data from several countries after going through 1 year of the pandemic, showing the evolution and peaks of incidence, thus being more reliable in predicting the nature of this virus. However, a 2-3 year study would be required to have a definite proof about whether the virus is seasonal or not.

So far, the seasonality of COVID-19 (if exists) appears to be more pronounced at higher latitudes; larger seasonal amplitudes of environmental indicators are observed in higher latitudes. However, the true seasonality of COVID-19 may not be noticed, if noticed might not be strong enough to conclude, in the first years of pandemic since waves of infections are noticed worldwide with new strains which necessitate a longer period of observation to be conclusive for seasonality.

\section{Conclusion}

After over one year with pandemic SARS-CoV-2 a seasonal pattern shows-up, this pattern is affected by factors as; temperature, latitude and application of primary protection. To identify the optimal seasonality pattern, the latter should be taken in consideration.

\section{Limitation}

This study was done depending on a one year interval only, yet it was supporting the seasonality theory.

\section{Conflicts of Interest}

The authors declare no conflicts of interest.

\section{Funding}

None. 


\section{References}

1. Z. Wu, J.M. McGoogan. Characteristics of and important lessons from the coronavirus disease 2019 (COVID-19) outbreak in China: summary of a report of 72314 cases from the Chinese center for disease control and prevention J Am Med Assoc, 323 (13) (2020), pp. 1239-1242.

2. Dhama K, Khan S, Tiwari R, Sircar S, Bhat S, Mali YS, Singh KP, Chaicumpa W, Bonilla-Aldana DK, \& Rodriguez-Morales AJ. (2020). Coronavirus Disease 2019-COVID-19. Clinical microbiology reviews, 33(4), e00028-20. https://doi. org/10.1128/CMR.00028-20.

3. WHO. Rolling updates on coronavirus disease (COVID-19). Available from: https://www.who.int/emergencies/diseases/novel-coronavirus-2019/ events-as-they-happen

4. WHO. COVID-19 Explorer. Available from: https://worldhealthorg.shinyapps. io/covid/.

5. Cohen J. Why do dozens of diseases wax and wane with the seasons - and will COVID-19?. Science. Available from: https://www.sciencemag.org/ news/2020/03/why-do-dozens-diseases-wax-and-wane-seasons-and-willcovid-19.

6. CDC. The Flu Season. Available from: https://www.cdc.gov/flu/about/ season/flu-season.htm\#: : :text=(6\%20seasons).-,When\%20is\%20the\%20 flu\%20season\%20in\%20the\%20United\%20States\%3F,last\%20as\%20 late\%20as\%20May.

7. Burra P, Soto-Díaz K, Chalen I, Gonzalez-Ricon RJ, Istanto D, Caetano-Anollés G. Temperature and Latitude Correlate with SARS-CoV-2 Epidemiological Variables but not with Genomic Change Worldwide. Evolutionary Bioinformatics. January 2021. doi:10.1177/1176934321989695.

8. National Academies of Sciences, "Medicine, rapid expert consultation on SARS-CoV-2 survival in relation to temperature and humidity and potential for seasonality for the COVID-19 pandemic (April 7, 2020)" (Report, The National Academies Press, Washington, DC, 2020).

9. CDC. Principles of Epidemiology in Public Health Practice, Third Edition; An Introduction to Applied Epidemiology and Biostatistics.
Lesson 1: Introduction to Epidemiology; Section 8: Concepts of Disease Occurrence. https://www.cdc.gov/csels/dsepd/ss1978/lesson1/section8. html\#: :text=Environmental\%20factors\%20include\%20physical\%20 factors,the\%20availability\%20of\%20health\%20services.

10. Tosepu R, Gunawan J, Effendy DS, et al. Correlation between weather and Covid-19 pandemic in Jakarta, Indonesia. Sci Total Environ. 2020;725:138436

11. Hussein, Nawfal \& Naqid, Ibrahim \& Musa, Dildar. (2020). The Impact of Breaching Lockdown on the Spread of COVID-19 in Kurdistan Region, Iraq. Avicenna Journal of Clinical Microbiology and Infection. 7. 34-35. 10.34172/ ajcmi.2020.07.

12. Carleton T, Meng KC. Causal Empirical Estimates Suggest COVID-19 Transmission Rates Are Highly Seasonal. Available online: https://www. medrxiv.org/content/10.1101/2020.03.26.20044420v1.

13. Sajadi MM, Habibzadeh P, Vintzileos A, Shokouhi S, Miralles-Wilhelm F, Amoroso A. Temperature, humidity, and latitude analysis to estimate potential spread and seasonality of coronavirus disease 2019 (COVID-19) JAMA Netw. Open. 2020;3:e2011834. doi: 10.1001/ jamanetworkopen.2020.11834

14. Ficetola G.F., Rubolini D. Climate affects global patterns of COVID-19 early outbreak dynamics. medRxi. 2020 DOI: 2020.03.23.20040501.

15. Merow C, Urban MC. Seasonality and uncertainty in COVID-19 growth rates. medRxiv. 2020 doi: 10.1101/2020.04.19.20071951.

16. Qi H, Xiao S, Shi R, Ward MP, Chen Y, Tu W, Su Q, Wang W, Wang X, Zhang Z. COVID-19 transmission in Mainland China is associated with temperature and humidity: A time-series analysis. Sci. Total Environ. 2020;728 doi: 10.1016/j.scitotenv.2020.138778.

17. Sajadi M.M., Habibzadeh P., Vintzileous A., Shokouhi S., Miralles-Wilhelm F., Amoroso A. Temperature, humidity, and latitude analysis to estimate potential spread and seasonality of coronavirus disease 2019 (COVID-19) JAMA Network Open. 2020;3 e2011834. 